\title{
Postdigital Dialogue
}

Petar Jandrić (Zagreb University of Applied Sciences, Croatia), Thomas Ryberg (Aalborg University, Denmark), Jeremy Knox (Edinburgh University, UK), Nataša Lacković (Lancaster University, UK), Sarah Hayes (Aston University, UK), Juha Suoranta (Tampere University, Finland), Mark Smith (Loughborough University, UK), Anne Steketee (Chapman University, US), Michael Peters (Beijing Normal University, China), Peter McLaren (Chapman University, US), Derek R. Ford (DePauw University, US); Gordon Asher (The University of the West of Scotland, UK), Callum McGregor (Edinburgh University, UK), Georgina Stewart (Auckland University of Technology, New Zealand), Ben Williamson (University of Stirling, UK); Andrew Gibbons (Auckland University of Technology, New Zealand)

\section{Introduction (Petar)}

Dialogue is an exchange of information between people, a linguistic format which supports such exchange, a form of art, a type of inquiry, an approach to pedagogy, a precondition for social change, and much more. In Western philosophical tradition, argues Michael Peters, dialogue comes down to us "through the Platonic dialogues, a kind of dramatization of the dialectics where Socrates in dialogue with another drives the opponent to an elenchus or contradiction. At this point, the game of arguing for the sake of conflict, or eristics, is over." (in Jandrić 2017: 30) In the history of Western thought,

we can talk of many kinds of dialogue based around the innovations of Nietzsche, Kierkegaard, and Buber (the existential encounter); Heidegger and Gadamer (the hermeneutical model of participants as co-seekers of truth aiming at consensus); the critical dialogue of Habermas ('the ideal speech situation' without any form of coercion driven by argumentation alone); Freire's dialogue as cultural action; Rorty's conversation based on Gadamer and Oakeshott ('the conversation of mankind'), Wittgenstein's and Derrida's genres of dialogue as forms of speaking to oneself as an interior dialogue; and so on. (ibid: 31 )

Digital technologies have provided new affordances for dialogue: Internet Relay Chat (IRC) and its successors, Internet forums, Internet pages editable by everyone (i.e. Wikipedia), sharing short messages (i.e. Twitter), sharing images (i.e. 4chan), sharing video (i.e. YouTube), sharing information across formats (i.e. Facebook) ... New platforms and formats appear by the day, and irreversibly change the way we 'read' and 'write' information in digital environments (Peters and Jandrić 2018: Chapters 12-13). Furthermore, "we are increasingly no longer in a world where digital technology and media is separate, virtual, 'other' to a 'natural' human and social life" (Jandrić et al., 2018: 1). There is no such thing as 'purely digital' dialogue or 'purely analogue' dialogue; the first has clear biological aspects, and the second is always informed by the first. Situated within the powerful dialectic "between physics and biology, old and new media, humanism and posthumanism, knowledge capitalism and bioinformational capitalism" (ibid: 4), today's dialogue is inherently postdigital.

Between 2012 and 2017 Petar Jandrić has conducted a series of 16 conversations about learning and research in the age of digital reason. Conducted between 20 interlocutors working 
in the fields of history, philosophy, media theory, education, practice, activism, and arts, and shaped by feedback of numerous (often anonymous) reviewers and editors, these interchanges build a large overreaching dialogue. In his approach, Jandric had not been seeking truth or consensus between the interlocutors. Inspired by his collaboration with Michael Peters (Peters and Jandrić 2018) he set up the dialogues as an experiment in collective knowledge making and dissemination. Building on works of Pierre Lévy, this experiment is an attempt of developing a specific form of collective intelligence defined as

a scientific, technical and political project that aims to make people smarter with computers, instead of trying to make computers smarter than people. So, collective intelligence is neither the opposite of collective stupidity nor the opposite of individual intelligence. It is the opposite of artificial intelligence. It is a way to grow a renewed human/cultural cognitive system by exploiting our increasing computing power and our ubiquitous memory. (Lévy in Peters 2015: 261)

Jandric collated these dialogues in the book Learning in the age of digital reason (Jandrić 2017). One year after its publication, the book has been reviewed by Sarah Hayes, Nataša Lacković, Jeremy Knox, Gordon Asher, Mark Smith, Callum McGregor, and Anne Steketee. It has also inspired a 3-person book review symposium written by Juha Suoranta, Thomas Ryberg, and Derek Ford. Finally, in April 2018, the book has been a topic of book symposium at the American Educational Research Conference (AERA) with Peter McLaren, Michael Peters, Derek Ford, Sarah Hayes, Nataša Lacković, Petar Jandrić, and an audience of approximately 30 people. These reviews and symposia contributions have not merely commented on Learning in the age of digital reason - responding to Jandrić's invite, they continued dialogue far beyond the book and offered numerous fresh insights.

In order to continue this dialogue, reviewers and symposia participants have been invited to co-author this collective article by generalizing their earlier critiques or by providing completely new insights. Previously written reviews have been made available to co-authors, and co-writing took place in a shared online document. During Petar's visit to New Zealand, Georgina Stewart gave very insightful remarks about the research value of dialogue, so she was invited to contribute to the Discussion. Open review for the article is provided by Ben Williamson and Andrew Gibbons. Through postdigital dialogue between its co-authors and reviewers, this article offers a snapshot of our current insights into postdigital dialogue and its place within today's education and research.

\section{The postdigital challenge}

\section{Dragging the digital into the mud (Thomas)}

It may seem ironic to engage in debates of the 'postdigital' in an era so deeply permeated by 'digitalisation' discourses and initiatives. Across all sectors there is currently a strong focus and push for 'digitalisation'. Whether to remain competitive, provide better teaching and learning, healthcare, administrative services or governance, 'the digital' is envisioned as a means to improve, innovate or disrupt the existing. Saturated by technical jargon, such as version numbers (Welfare 2.0, Industry 4.0), digital technologies, Big Data, machine learning, 
algorithms, AI, Internet of Things, and Robotics, are mobilised as rhetorical devices to promote particular 'socio-technical imaginaries' which are:

[...] collectively held, institutionally stabilized, and publicly performed vision of a desirable future that $\mathrm{i}$

$\mathrm{s}$ animated by shared understandings of forms of social life and social order and made attainable through the design of technological projects. Such futures are produced by particular social groups within specific social contexts, and they are also projected through the design of particular kinds of technologies to express a view of particular futures in which those kinds of technologies are imagined to be integral, embedded parts. (Williamson 2015: 2)

In these 'imaginaries' there is a tendency to view the 'digital' or 'technology' as existing in a realm of ethereal bits and bytes unencumbered by material bindings, as suggested by terms such as 'the cloud' and 'online'. And further, there is a tendency to believe that the transformation and re-engineering of 'bits and bytes' into algorithms, AI or machine learning are based on solid, pure, rational scientific reasoning anchored in data science, statistics, mathematics promising to ground education and learning in scientifically and data informed decisions rather than the 'gut-feelings' of teachers. However, the digital is far from ethereal and existing 'online' or in the 'cloud'; it depends on deeply material forms such as processors, circuit boards, hard disks, data centres, and human labour. Thus, the digital is firmly rooted in the material world drawing nourishment in the form of earthly raw materials such as gold, copper, tin (often painstakingly retrieved and assembled by low-wage workers or even children) and with electrical power pumping through its veins drawn from the burning of fossil fuels. And while algorithms, AI and machine learning are certainly outcomes of scientific reasoning, they are also prone to biases and are underpinned by particular (often quite simplistic) understandings of pedagogy and learning in the case of educational technologies. Adding to this, digital technologies are implemented in complex, dynamic, messy, political social and organizational contexts that are constantly changing and that will shape, and be shaped, by 'digitalisation'.

Therefore, the postdigital is about dragging digitalisation and the digital - kicking and screaming - down from its discursive celestial, ethereal home and into the mud. It is about rubbing its nose in the complexities of everyday practice, such as managing a class of sevenyear olds working on tablets (half of them not charged, and the other half with links to dubious sites); the realities of gender- or racial bias of algorithms or how notions of imagined efficiency gains brought about by 'the digital' impact on work-life balance in organisations.

\section{Postdigital thinking (Jeremy)}

Perhaps paradoxically, if we are indeed entering a 'postdigital' era, it appears to be characterised by more in the way of digital devices, infrastructure, code, and software saturating our everyday lives, even when we are not directly 'in touch' with it. To be on the 'worse end' of the 'digital divide' does not mean that you live an entirely 'analogue' life, unaffected by the encroachments of digitisation. Rather, it means that you have less agency in the digital era, and that you are undoubtedly impacted to a greater extent by a technology-infused global capitalism. 
In that sense, in the 'postdigital' world, global humanity is more digital than it has ever been, whether one has access to the latest consumer gadgets, or not.

What does it mean, then, to be 'post' digital; to have, in some way, 'moved beyond'? One way of responding to this would be to suggest that the 'postdigital' is much more about a way of thinking than it is about a technology, if one can hold those things distinct, at least for the moment. One might think of the 'post' as signalling a critical holding-to-account of the broad cultural understanding that the term 'digital' has come to represent. While the early Internet was characterised by notions of 'virtual' reality and a 'cyberspace' of 'otherness', the 'social' and participatory understanding of the web ('2.0') is very quickly being eroded, and replaced, by a growing appreciation of the automated, algorithmic, and data-driven functions which underpin it. However, as an era of hyperbole around the transformational benefits of 'machine learning' takes hold, discussions about the purpose and functioning of education - or, 'human learning' - appears as important as ever.

Our current condition, then, is not only one in which digital technologies are simply more present or available in our lives, but, much more crucially, where we are 'delegating the work of culture - the sorting, classifying and hierarchizing of people, places, objects and ideas - to data-intensive computational processes' (Striphas 2015: 396). In educational practice specifically, analytic techniques promise to intervene in the teacherly tasks of identifying 'risky' behaviour (Lawson et al. 2016), influence student capacities to navigate educational pathways (see Sclater et al. 2016), or even to enhance that most treasured of educational pursuits, dialogue (see Knight and Littleton 2015). What is at stake in this current age of machine learning, then, is nothing short of the promise to fulfil the grand ambition of computer science: formalisation of - what might be considered the ultimate in intangibility - human performance (see Goodfellow et al. 2016).

In this drive for 'smartness' and efficiency, the postdigital offers two directions: not only a recognition of the increasing sense that any analytic separation of 'technology' and 'humanness' fails to articulate our contemporary condition, but also a critical call for getting more out of this relationship. Alongside prominent campaigns to instil 'computational thinking' amongst children in the US (see https://code.org/), the UK (see http://www.yearofcode.org/), and elsewhere, or to promote 'data driven decision-making' amongst teachers (van Barneveld et al. 2012), we must also find ways to promote and establish thinking and decision making as reflective political beings. To privilege a view of the world as a discrete set of computational 'problems' (Morozov 2013), or to foster an uncritical faith in the mythology of objective data (Boyd and Crawford 2012), would seem to greatly diminish our capacity to think, and blind us to the inherent biases of algorithms (O’Neil 2017), and the inequalities (Eubanks 2017), sexism (Wachter-boettch, 2017) and racism (Noble 2018) that they reproduce. A postdigital education should therefore reject the banality of 'non-thinking' our way through the rise of learning machines, and cultivate the kind of thinking and learning we might associate with a critical citizen of our times.

\section{Artefact mediation and multimodal postdigital dialogue (Nataša)}

Technology does not act alone, but dialogue does not act alone either, or better to say, it is not a singular entity. Many authors have noted the importance and benefits of dialogue for knowledge development and scholarship. For example, Jandrić (2017) applies a dialogic 
approach for the purpose of celebrating, merging and disseminating collective knowledge at an intersection of education and the digital. The verbal character of dialogue is obvious in speech and writing. However, even Socrates must have developed dialogue with/via/from a plethora of artefacts and non-verbal modes of communication and cognition (e.g. symbols, diagrams, maps, drawings, external and mental images, image metaphors and objects). Indeed, how we think, interpret and voice in a dialogic exchange develops through the profusion and connectedness between the body and the mind, the image and the concept, the artefact and the dialogue, the art and the science, the technological and the human (e.g. Stafford, 1993; 1996; $1998 ; 2001 ; 2007)$. When it comes to dialogues in education - e.g. the dialogue stemming from educational research, philosophy and pedagogy - the move towards more integrative approach to artefacts is further based on the fact that:

(i)n the last two decades, the global movements of multimodality (Jewitt, Bezemer and O'Halloran, 2016; Iedema, 2003; Jewitt, Kress, Ogborn and Tsatsarelis, 2001; van Leeuwen, 1998), new literacies (Freebody and Luke 1990; Knobel and Lankasher, 2006; Lankshear and Knobel 2007) and multiliteracies (Anstey and Bull 2006; Cope and Kalantzis, 2000; New London Group, 1996) have been paving the way for renewed understanding of communication and education processes, especially in relation to technology mediation.

(Lacković

Such renewed understanding means that those processes include but go beyond language, bringing to higher education research and teaching the artefacts that surround us, and are a part of us (Lacković 2018; Hallewell and Lacković 2017; Lacković 2010). As Susi (2005: 2110) argues, "one of the fundamental findings of cognitive science is that artefacts shape cognition and collaboration (Woods, 1998)", building on the Russian cultural-historical school in psychology of the late 1960's and 1970's (Vygotsky 1978). Artefacts are commonly overtly verbalised (mentioned) in the dialogue, or they are mental representations, such as associations, metaphors and images in interlocutors' minds (Lakoff and Johnsen 2003), or they mediate dialogue by the power of its external material presence and visibility, socially infused affordances, functionality and affective immediacy (Lacković 2018; Stafford 1998). As dialogue requires an on-going engagement and interpretation, multimodal and semiotic approaches offer tools and language to uncover layers and aspects of this omnipresent interpretative dimension of the dialogue. With the established fields of social, bio, zoo, eco and many other approaches to semiotics, multimodality, and emerging fields of philosophy such as edusemiotics, a scope for exploring the postdigital is wide open.

What this means for postdigital dialogue, research and practice? Within the postdigital discourse, the "old" and "new" media are considered as cohabiting artefacts, brought into new relationships, reinvented, and repurposed (Cramer 2014; Jandrić et al. 2018). The postdigital disruptions "brought upon by digital information technology" (Cramer 2014) and the "life" of new and old media can be understood more fully by applying multimodal and semiotic methodologies in conjunction with appropriate theories (e.g. critical, posthumanist, sociomaterial, sociological, psychological), than by applying language and linguistic methods alone. 


\section{Exchanging new values in a postdigital dialogue (Sarah)}

Dialogue is a valuable exchange which continually reaffirms collaborative possibilities for humanity, through discourse. It can take the form of open, insightful and exciting interchanges, like the rich and varied conversations that shaped Learning in the Age of Digital Reason (Jandrić 2017). Or instead, dialogue may be constrained, if language is loaded with economically-based assumptions and individualised agendas, that restrict how we might collectively imagine alternative futures. In educational policy for human learning through technology across recent decades, authentic dialogue to build new knowledge has stalled. A popular discourse (on a global scale) has emphasised instead what technology (not people) 'achieves' and 'enhances' (Hayes and Jandrić 2014; Hayes 2015; Hayes and Bartholomew 2015; Hayes, 2018). This focus in language on an 'exchange value' (Marx 1867/2003) from technology has hampered more critical understandings of how humans and technologies 'mutually constitute' each other (Mackenzie and Wajcman 1999). However, a rational political logic that insists technology is an external force able to 'fix' societal issues (Peters, Jandrić and Hayes 2018) overlooks three powerful considerations. Firstly, this discourse fails to acknowledge that humans are technology. Rikowski reminds us that if 'free-floating technology was a reality' then we could simply halt its entry into our bodies (Rikowski 2003: 140). Secondly, humans are capital, and 'technology is an expression of capitalist social relations' (Rikowski 2003: 140). Thirdly, language in use, as discourse, can either reveal, or conceal, these powerful revelations.

The physical tools that once sustained human lives may have merged with virtual instruments and automation in a digital age, but in contemplating postdigital life, dialogue concerning the distribution of human labour is a constant. The labour power of humans that yields 'value' does not stand apart from people. It can never be attributed to technology alone, in the form of enhancement, despite the persuasive arguments of politicians. Yet the drive to enhance the quality of labour power itself, in the form of surplus value and in the service of capitalism continues, despite the physical limitations of humans (Rikowski 2003: 148).

We now face a significant challenge to be addressed, as we embark on a postdigital dialogue. This lies in where we choose to place 'value' in our discourse about technology. The technological fruits of human labour now flow through our bodies in unprecedented ways, as we are surgically repaired, enhanced and enabled by the devices humans have created. Yet still we are linguistically separated from our tools. In a sense the concept of 'post' has resided with us throughout history. Who can say when 'post anything' starts or ends, but still 'post' keeps us hopeful that new possibilities remain. In the postdigital, we now need to open new dialogues, with an awareness of the value of these exchanges, played out through the 'labour of our words' (Hayes forthcoming). If we do nothing further, then let's continue this dialogue and finally disrupt forever, the myth that technology acts alone.

\section{Postdigital critical pedagogy}

\section{Postdigital critical pedagogy as superabundance of education (Juha)}

In the postdigital age we need a new language, theory and praxis, of postdigital critical pedagogy, which creates a horizon of solidarity in learning and co-operation. The new language of postdigital critical pedagogy will be critical towards a commercial-capitalist Internet controlled by the corporate-state-military-complex, and which will celebrate ordinary peoples' 
volunteer and commons-based Internet. A postdigital critical pedagogy describes, criticizes, and captures the state and the socio-political landscape of learning after the digitization and marketization of the channels of education through which we communicate; that is, after the fact that capitalist digitalization has immersed into education and broken the traditional boundaries of formal and informal teaching and learning; the digital landscape in which old unreflexive certainties of learning have turned into reflexive uncertainties.

A postdigital critical pedagogy reclaims the digital sphere as commons. Bringing people together and providing them with an access to all human knowledge are among the most essential features of postdigital critical pedagogy both in theory and practice. This feature of critical pedagogy can be summed up with the idea of horizontal communication. Postdigital critical pedagogy emphasizes horizontal networks of communication and distributed media where people can contribute richly: give and take information, share ideas, debate openly, and send and receive information for free. In other words, it can be considered as a new stage in, or an extension of, Paulo Freire's pedagogical model: a globally distributed "pedagogy of all people in the process of permanent liberation" (Freire 1970: 54). A postdigital critical pedagogy aims at bringing people together and connects them in various shared learning tasks. As Kenneth Gergen has put it:

The aim, then, is not that of producing independent, autonomous thinkers mythological creatures at best - but of facilitating relational processes that can ultimately contribute to the continuing and expanding flow of relationships within the world more broadly. (Gergen 2009:

A postdigital critical pedagogy wants to further the Internet that is useful to the people that they can shape for their own uses. It is thus vitally important as Paula Allman has put it, that " $[\mathrm{P}]$ eople need to experience and feel the difference, rather than just hear or read about it, if their consciousness is to undergo an authentic change" (Allman 1999: 104). In the postdigital era education will not be a privilege as the ruling class would like to have it, but a mass movement turning students from potential slaves for commodity production to active producers who desire to act in the Marx's dictum: "To each according to their needs, from each according to their abilities."

The ultimate goal of postdigital critical pedagogy in the postdigital era is the production of surplus consciousness and educational superabundance - as Rudolf Bahro, an eco-socialist philosopher and educational reformist from the now defunct German Democratic Republic, stated already in the late 70s:

The production of surplus consciousness that is already in train spontaneously must be vigorously pursued in an active way, so as to produce quite intentionally a surplus of education which is so great, both quantitatively and qualitatively, that it cannot possibly be trapped in the existing structures of work and leisure time, so that the contradictions of these structures come to a head and their revolutionary transformation becomes indispensable (Bahro 1978: 404, cited in Gorz 1997: 89). 
Living in a world in which digital creativity is taken for granted as it intertwines with human behaviour, Petar Jandrić and Peter McLaren (2014) suggest that critical pedagogues need to engage with this challenge. In my capacity as an artist cum teacher, postdigital dialogue is associated with practitioners such as Roy Ascott, media arts pioneer and mind-blowing wordsmith. When I met Roy in the late 80 s, I had no idea that thirty years on I would still be using some of his terminology and still be regarded as 'out there' by colleagues in art, design and media education. Roy is probably best known for his work in the field of 'technoetics' (2008), a convergent field of practice that seeks "to explore consciousness and connectivity through digital, telematic, chemical or spiritual means".

When thinking about Petar's comment - that we live in a world in which digital technology and media are inseparable - I was reminded of my own complicity in this scenario. During the thirty years since meeting Roy the influence of digital creativity has permeated the classroom. I have increasingly struggled to persuade colleagues and students of the need to focus on our critical consciousness - Paulo Freire's post-Marxist conscientização. I mention my complicity: I experimented with ground-breaking video technology as we moved from analogue film and video to digital production in the $80 \mathrm{~s}$; used the Internet to distribute artists' moving image in the 90s; created video and film artworks as the personal computer evolved into a creative workstation; noted the attendant effects (physical, social and political) upon student practitioners as they moved towards laptops and 'hot-desking'. I share a responsibility for a commodified understanding of the relationship between digital technologies, the creative media and education.

Reading Petar's collection of conversations, Learning in the Age of Digital Reason (2017) guided me towards revisiting that terrible question: 'What can I do to stop my students being guided down a sanitory, digitised pan?' As Guy Debord comments: “in a world where everything is back-to-front, a truth is really a lie" - (2006: 768). For instance, what is my position as a critical pedagogue as I inadvertently promote Adobe's raft of creative software? Is this an unspoken lie? Learning software does not develop critical reasoning skills that will problematise cultural commodification but fosters dependency on a set of operative skills. It narrows our scope for critical dialogue in the studio classroom. But does postdigital analogue practice fare any better in the critical classroom? How might, for example, the analogue practice of drawing on paper in the media arts class support critical dialogue?

Drawing dots and vectors to visualise meme-making is one method - I use the analogy of worker ants moving a stick away from their nest to great effect. Animation is another approach, as exemplified in the online Artists' Moving Image resource (Smith 2017). I have previously commented on how observational drawing in schools decontextualises cultural production and suggested moving-image focused activities (Smith 2011; 2012a; 2012b; 2017) that may support critical pedagogies in challenging this approach to art education. Amazingly, I was gifted another potential strategy this week at the Thinking Through Drawing symposium. This annual event explores cognitive processing through the act of drawing. Melissa Button (Arizona State University) asked us to separate our senses - taste, touch, etc. - and effectively decontextualise the act of drawing. We were given a paper bag and asked to draw five different representations of the invisible object within — in my case, a chunk of pineapple. Through the removal of all but one of the five principal senses, Allison had effectively asked me to decontextualise the hidden pineapple. I had to think and guess at the real 'meaning' of the 
pineapple without looking. The final reveal allowed the contextualisation of the fruit. Through introducing sight, I was able to recognise the 'truth'.

What struck me afterwards was how Melissa had cleverly opened my eyes to the possibilities of using the same process of desensing (as in telecommunication and signal interference) to elicit critical dialogue amongst students. We could use this process of decontextualisation (of our sense-informed, empirical perceptions) to underline the need to contextualise the production of cultural artefacts (Adorno 2002). Diverting our perceptions of production is a purpose of the 'vectoral class' (Wark in Jandric 2017: 105-135), camouflaged by the guise of technological determinism and liberal 'false generosity' (Freire 1970). Within visual arts and media programmes, our postdigital critical dialogue must attempt to illuminate this lie. Such 'contextualised, question-posing and problem-solving' dialogue (Phillips, cited in Asher 2017: 13) is essential to developing critical creative minds.

\section{Hope at the confluence of new rivers (Anne)}

At times, they feel hopeless when looking into their futures. The undergraduate classroom conversations that have surprised me the most this past year have been ones focused on technology, virtual spaces, digital identities, and resulting student emotional fallout. We begin class unpacking a study on mental health and end class with student after student expressing virtual trauma from embodied experience. The ferocity of this student response demonstrates the resonance they feel with the increasing prevalence of young adult major depressive episodes and anxiety (Mojtabai, Ofsan, \& Han 2016), linked to the growing virtual habits of their generation (Twenge 2017). Of course, the counter viewpoint can also be supported. Domoff et al. (2017) reflect that we might be asking the wrong questions about the impact of virtual spaces on youth - it might not be the amount of time young people spend online but rather the use of that time. The slight shifting of perspective changes the trajectory of both the research question and the resulting reflections.

This "slight shifting of perspective" is a theme that I would like to explore as I consider the complex conversations about postdigital dialogue. McLaren (in Jandrić 2017: 172) notes that digital processes might be reproducing cultural assumptions while silencing aspects of nonWestern cultures. Bianchi (2018: 63) cautions, "Even if western researchers are aware of their own misunderstandings of cultural information and traditions, they may still unknowingly have a negative effect on cultural knowledge because of the influence they wield as western individuals". This western mindset is one I continually interrogate and work to shift in my reading and conceptualizing. Postdigital dialogues provide a nudge, but I also actively eavesdrop for the quiet conversations around me, ones that might not be my birthright, my earthright, but ones that can be my teachers.

Raheja (2017) encourages readers to imagine "new ways of relating to one another and living deep connection with the land and all its forms of life" at the confluence of digital rivers and imperiled rivers. Gliding down new rivers, I am gently eavesdropping on transindigenous dialogues (Allen 2012). From these conversations, where I am an interloper, I catch the whisper of conversation where indigenous teachers, through postdigital dialogues, share that wampum "has the potential to re-vision the intellectual history of technology" (Haas 2008: 78); that digital spaces "are indigenous territories" (Hearne 2017: 6); that expressions become reexpressed, "Employing animation as a tool of decolonization, Indigenous women's innovations 
prompt a reexamination of scholarship on the genre" (Romero 2017: 60), and that even the particulars of hardscaping can be interpreted indigenously by "finding ways outside of the hardware constraints and software platforms to engage the indigeneity of technology" (Hearne \& LaPensée 2017: 35). Barbrook notes that people shape the digital (in Jandrić 2017: 101). It's not that these are indigenous expressions of Western postdigital dialogue; it is that these are embodied and encultured ways of knowing.

And to reconcile two visions of an indigenous, connected world with a mechanical, objectified world, Vásquez (2010: 280) posits: "If we are truly talking about diversity and respect, it is imperative that there be conversation and dialogue between both cosmovisions, a situation which is still not resolved in school curricula or within institutions in general". Dialogue through postdigital conversations offers the possibly to unlearn in order to relearn, together; this is hope.

\section{Postdigital politics}

AERA 2018 symposium (Michael, Sarah, Peter, Derek, Nataša, Petar)

In April 2018 Petar Jandrić organised a symposium 'Learning in the Age of Digital Reason' at the American Educational Research Conference (AERA). Symposium participants were Peter McLaren, Michael Peters, Derek Ford, Sarah Hayes, Nataša Lacković, Petar Jandrić, and an audience of approximately 30 people. The discussion covered a lot of ground, as participants approached contemporary opportunities for dialogue from their own (very different) perspectives. Yet, it is fair to say that the most prominent question in the discussion was: How do we move the dialogue beyond a mere feel-good exercise of scratching each other's' back and make it truly political?

Michael Peters' presentation 'Learning, Creative Col(labor)ation, and Knowledge Cultures' has exposed multiple functions of dialogue: dialogue as learning, dialogue as creative col(labor)ation in knowledge creation, and dialogue as a building block for the larger project of knowledge cultures. On that basis, Michael showed that the contemporary postdigital dialogue provides a good fit to Pierre Levy's program of collective intelligence. In 'A Body of Knowledge That Neglects the Body?' Sarah Hayes explored linguistic aspects of postdigital dialogue. Based on Critical Discourse Analysis (CDA) of 2.5 million words of UK government policy and university strategy texts written between 1997 and 2012 (an earlier analysis of the same phenomenon can be found in (Hayes and Jandrić, 2014)), and showed that contemporary policy texts seem to avoid human beings and their agency in favour of faceless technodeterminist statements such as 'using technology to enhance learning'. Sarah's presentation showed some limitations of Levy's approach to postdigital dialogue - radical equality of human and non-human actors - and emphasised the need to bring agency firmly in the hands of human beings.

In 'The Dialogical Challenge of Revolutionary Critical Pedagogy', Peter McLaren reminded of the rich tradition of dialogue within critical pedagogy and beyond. Peter emphasised the roots of Paulo Freire's dialogic approach in (radical) pedagogy of love, thus expanding Sarah's call to return agency to human beings towards intimate connections such as feeling and emotion. Thus, Peter concluded that postdigital dialogue firmly stands between technological and non-technological, the logical and the emotional - and one cannot be thought of without the other. 
Finally, in 'Politics and Pedagogy In the Age of Digital Reason: From party to Party' Derek Ford used the works of Jodi Dean (2016) to criticize Jandrić's 'convivial party' approach to dialogue that Learning in the Age of Digital Reason (Jandrić, 2017) embodies and emphasised the need to move towards the political organization form of the Communist Party. Noticing that the two kinds of party bear an intimate connection, Derek emphasized that the 'convivial party' - exhibited in Jandrić's book, at the symposium, and also in this article - is a pre-requisite for other, more mobilizing forms of political Party which is able to organize and mobilize the conviviality into a political force capable of winning power. Yet he observed a crucial educational component of the Party that is latent in Jandrić's work and absent in theorizations of the party: the test. Indeed, Jandrić in many ways approaches the party of dialogue as a test proctor. He is constantly testing his interlocutors: What about this? You once said $x$, but what about $y$ ? He argued that in the postdigital era, the Party needs to test itself, the masses, and the movement in this way.

Nataša Lacković responded to these presentations by pointing that all presentations criticized Learning in the Age of Digital Reason (Jandrić 2017) for author's 'lack of political attitude' and 'anything goes' approach. In several ways, participants insisted that digital technologies are inextricably linked to dialogue, yet in in its postdigital forms, we need to move away from novelty and convenience of automatization and instant communication and emphasize human agency and its complex relationships to emotions, artefacts and feelings. Participants further recognized that postdigital dialogue, at least when aimed at knowledge production and dissemination, is not competitive. Unlike some dialogical formats which are very popular in neoliberal education, such as debate, postdigital dialogue is not aimed at winning but collaboration - and collaboration requires in a 'safe space' where people can expose their opinions to constructive critique. Finally, it was recognized (both between presenters and within the audience) that this theorizing is just a small part of a larger social role of postdigital dialogue. In order to gain more power and agency, postdigital dialogue as party should be expanded to (and understood as dialectically intertwined with) more direct forms of political organisation.

\section{Postdigital delegitimation, paranoia, and political pedagogy (Derek)}

As a contradictory political and educational landscape, the postdigital age introduces new problems and possibilities for horizontal and vertical pedagogical praxis. We can trace this development and the problems arising from it in multiple ways. Lyotard, for example, argues that the delegitimation of the grand narratives of modernity result in part from "the demand for legitimation itself" (1984: 39), as the process of legitimation is one without end (one has to prove a proof, and so on, ad infinitum). Without a final stop or block to this, we are left with the terror of the performativity criterion, on one side, and the postmodern sensitivity to justice and the unforeseeable, on the other side. In other words, the delegitimation of grand narratives both opens space for little narratives to emerge horizontally and facilitates the vertical concentration of power in capital and the state via the performativity criterion.

The postdigital manifestation of this conflict surfaces every time we research on the Internet. On the one hand, various sources and media are horizontally laid out in tabs in front of us. We transition seamlessly between YouTube clips by anonymous bloggers, mainstream and alternative news articles, academic database search engines, Twitter feeds, and so on. Each 
have different stakes, references, and discursive rules, and incommensurability abounds. And yet behind the screen the performativity criterion determines in advance the probability and possibility of my exposure to each source, and capital and state struggle to legitimize some sources and delegitimize others. We have a concentration of power under the guise of horizontality. As such, educational research and practice must inhabit the postdigital age paranoically, and political praxis must inhabit it forcefully.

Inhabiting the postdigital paranoically means that pedagogy has to always be sceptical, searching, and uncertain. Jason Wallin and Jennifer Sandlin (2018: 14) delineate three aspects of a paranoid education: first, paranoia alerts us constantly to the deep structures that shape our lives; second, it helps us "map compossible worlds that exist alongside the world as it is given"; and third, it pushes us to figure out and produce new ways of being and relating. The primary impulse of paranoiac pedagogy is, in sum, that of divestment from the present. In this way, paranoia is an operation of postdigital educational justice that constantly holds open the present as non-present, allowing the incommensurable and unforeseeable to breathe. While the delegitimation of grand narratives nourishes the pedagogical imagination, the political responds by organizing force. Two related but distinct tasks (Ford 2018). The vertical arrangements of power operating behind the screen of horizontality have to be confronted and, ultimately, defeated to fulfil the digital promise of a networked world of equality, or to actualize the new lines of flight generated through paranoiac pedagogy.

\section{The postdigital: dialogue, democracy, and dissensus (Gordon with thanks to Leigh French and Antonia Darder for their helpful dialogical comments)}

Democracy is not a system of government, but the always conflictual and disruptive manifestation of the principle of equality. (Rancière in O'Connor 2012)

If the postdigital is explicitly politically committed (Jandrić et al. 2018) to the principle of equality - a 'political project', framed as moving beyond, predominantly positivistic, digitally mediated capitalist social relations (Peters 2015), towards new ways of being and becoming, living and relating (Ford 2018) - it seems important to appreciate both relevant contexts and a critical orientation and underlying values for informing resistances and alternatives; "not only does critical theory criticise current society, it also envisages a fairer, less alienated, more democratic world" (Brookfield 2005: 27). Thus, situating and exploring the role and purposes of postdigital dialogue within a critical paradigm (Asher 2015: 86) is consistent with a larger political project.

Our contemporary conjuncture is one of ongoing, integrated and intensifying crises, marked by growing social, political and economic polarisation - "the ecological crisis; the economic crisis of global markets; the political crisis of austerity; the social crisis of alienation; the cultural crisis of dislocation; the food crisis; the water crisis; the crisis of education" (Haiven 2014). One in which an inherently and increasingly authoritarian globalised neoliberalism, viciously anti-democratic in essence, is $a$ central cause of stark and rising inequalities and related intersectional oppressions, repressions and exploitations (Giroux 2018). A prominent role in the contemporary hegemonic, state-corporate nexus is performed by an increasingly neoliberalised and neoliberalising (of itself, those labouring within it, and the wider society it 
both shapes and is shaped by) higher education sector (Ball 2012; Asher 2017), as the university is further commodified and financialised, managerialised and metricised (Hall \& Winn 2017).

A critical paradigm and orientation situates the postdigital as speaking to both resistance to neoliberalism and the development of genuinely democratic and emancipatory alternatives to it (Kellner 2001). As such, it contributes to ongoing societal struggles and social movements working for eco-social justice. Central to such struggles is the radical democratisation of all spheres of society (and attendant relations), including the educational (Giroux, 2017); indeed, 'education for radical democracy' (Amsler 2015). As and for doing so, critical educational theory and practice (e.g. critical pedagogy/popular education (Cowden and Singh 2013; Kane 2001; Darder 2018, Freire 1970) foreground the role of dialogue, as focusing on:

- Democratic values and related emotions/affects (i.e., freedom, autonomy, participatory democracy/self-management, equality, solidarity, diversity, fairness/justice/equity, sustainability, creativity, trust, concern, respect, affection, love, empathy and hope (Albert 2006; Burbules 1993).

- A critical orientation for eco-social justice or 'praxis for liberation' (Kahn 2010).

- Individual and collective agency, voice, and empowerment (Freire 1970).

- Integral engagement with the emotional and psychological, affective and embodied (Darder 2015; 2017).

- The production of subjectivities and relations (ongoing processes of being and becoming), within social co-creation.

- Diversity and difference, divergence and dissensus.

Thus, dialogue is understood as prefigurative - as reflecting the very democratic values and objectives it espouses. Indeed, dialogue itself is conceived of, variously, as a value, as a means or process, as an end or objective (Taylor 1994) and regenerating form of collective engagement (Darder 2017). This is where the postdigital's focus on collective intelligence and knowledge making (Jandrić 2018; Peters \& Jandrić 2018) - as closely related to "mass intellectuality" (Hall \& Winn 2017), the "democratic intellect" (Davie 1990) and "conscientisation" as collective critical consciousness (Darder 2015; Roberts 1996) - and hence the collective democratic production of knowledges, values and desires, subjectivities and relations, can be seen to relate to and inform conceptions of genuinely radical or participatory, democracy (Amsler 2017; Bookchin 1990; Shalom 2008). And as with critical pedagogical notions of popular education, foregrounds the role of dialogue, as prefigurative.

If radical democracy is understood in terms of agonistic pluralism as centred on contestation (Mouffe 2013), "a theory that emphasises the positive aspects of political conflict as being generative of change - as well as the significance of an ethics of dissensus - as a means of attending to divergence and difference" (Helms et al. 2016), then an important consideration for radical democratic conceptions of critical postdigital dialogues is the role of dissensus. Grounded in a prefigurative dynamic, such dialogue cultivates awareness and welcomes the fostering of divergence and difference, diversity, and dissensus.

This calls forth a notion of dissensus that does not abolish political conflict (Rancière 2010), but rather supports conditions for democratic relations of communication in public encounters and deliberations. By doing so, it points in the direction of a liberatory project, one 
that strives towards relations of equality, mutuality and autonomy, rather than hierarchy and command (Weeks 2007). Such a critical notion of postdigital dialogue, in valuing contestation and dissensus, provides a necessary ethos for radically democratic life and transformative possibilities. Underpinning a political process focused on democratic participation, relations, practices and decision making across the different spheres of society (including education and research).

Chomsky (2018) reminds us: "There definitely are prospects of liberation, but it is necessary to take advantage of them, and it is often easy to retreat to superficial comfort zones restricted to what one wants to hear rather than exploring the wide range of possibilities made available by the new technology". Hence, I am suggesting a courageous conception of postdigital dialogue as a form of contemporary, prefigurative critical dialogue and collective democratic intellectuality, in an increasingly digitally mediated world. As such, postdigital dialogue generates genuine, substantive, radical or participatory democracy for the interactive, as opposed to the hierarchical and instrumentalising institutional communication (Gunn 2014) inherent to neoliberal approaches. This speaks to a postdigital dialogue committed to political struggles in, against and beyond capitalism (Holloway, 2016) and, not least, the neoliberal university (Asher 2015; Canaan 2011).

\section{The organic intellectual in a postdigital age (Callum)}

In Jandrićs Learning in the Age of Digital Reason (2017: 152) Henry Giroux reminds us that "critical pedagogy ought to adjust to the circumstances in which it finds itself." Wark (in ibid.: 114) understands this adjustment partly in terms of the need to create new vocabularies for the complex relations between ecological crisis, the "second nature" of the built environment and the "third nature" of digitised information networks. I take the modifier 'post' then, to mark a reflexive recognition of the need to think dialectically about the ways in which 'digital' immateriality is entangled in, and premised upon, regimes of environmental despoliation, exploitation and expropriation (Emejulu and McGregor 2016). Treating 'the digital' as an immaterial fetish object doesn't offer helpful roadmaps for political intervention in such a context.

Therefore, my own contribution to this experiment is to revisit the notion of the organic intellectual - that is, intellectuals who emerge from and are connected to the material interests of the oppressed and marginalised - in a postdigital context. Specifically, I would like to repose Stuart Hall's question, "are we thinking dialectically enough?” (Hall 1996: 232). Thinking dialectically directs us towards the ways in which "social relations" and "mentalities" become embedded in trajectory of any technological change "so as to mediate our relation with nature and the reproduction of daily life" (Harvey 2003: 22). A 'postdigital' conjunctural analysis might apply such a lens to analyse the 'Big Data' fetishism currently informing economic and social policy in particular contexts. An example is way in which the policy imaginaries of "smart cities" and "smart schools" (Williamson 2018), become entangled with social policy's more established fetishization of lifelong learning, as a panacea for retaining competitive advantage whilst tackling "social exclusion": the city as a "plastic" posthuman learning machine, rationally solving social problems through mining data, and delivering "sustainable growth" to boot. 
As Bassett (2015) observes, there is a question to be asked about how communities living through austerity might operate 'in and against' such narratives of expertise and informational abundance, which claim to be 'beyond representation' and even theory. The enduring challenge of organic intellectuality is that it is related to social purpose, which more often than not means swimming against a powerful tide. Hall (1992: 281) understood that in a context of power asymmetry, this meant knowing more than "traditional' intellectuals" ("if you are in the game of hegemony, you have to be smarter than "them"'), whilst also taking up the challenge of 'translation' (rendering the complex intelligible), without succumbing to epistemological populism, marked by an affective desire to trade in complexity for 'straightforward' answers. 'Big Data' fetishism on the one hand, and the irruption of authoritarian populism on the other, are different tendencies towards the abdication of critical thought. I speculate that one key task for organic intellectuals today, might be to move dialectically between these two tendencies, reframing populism as a starting point for critical educational engagement, and reframing digital literacy as something more than lifelong learning in the context of platform capitalism. This is, no doubt, a formidable challenge, but the connections are there waiting to be made for those willing to engage with Hall's question.

\section{Discussion}

Walking the talk: the analytic power of critical conversations (Georgina)

The expert interview is a recognised approach to qualitative data collection (Bogner, Littig, \& Menz 2009; Flick 2014). Expert interviews are seen as efficient for collecting good-quality data, but their status as research methodology remains under-theorised and uncertain, subject to disputes about knowledge, knowledge production and expertise. The academic literature contains a wealth of published interviews, but the interview genre is rare in educational research publishing.

Alexander Bogner and Wolfgang Menz distinguish three types of expert interview: "exploratory, systematizing and theory-generating expert interviews" (Bogner \& Menz 2009: 46). First, expert interviews are frequently used in exploratory research to gain an overview of a particular social field. Second, access to the expert's "knowledge of action and experience, which has been derived from practice" (46-47) provides relatively systematic and complete information: the "systematising" expert interview is the most widely-used of the three forms. The theory-generating expert interview aims at "the reconstruction and analysis of a specific configuration of knowledge" (55) in which the specialised knowledge of the expert has social relevance - "the power to produce practical effects" (54). The social relevance and power of the theory-generating expert interview underline its potential political significance.

Clearly these three types of expert interview differ in degree or emphasis, rather than being mutually exclusive. Depending on the orientation of the dialogue and the relationship between interviewer and interviewee, the expert interview can cross from data collection to analysis, in relation to a specific question contextualised within the dialogue. Bogner and Menz (2009: 68-69) also provide a typology of the relationality of the expert interview, where the interviewer is perceived by the interviewee as: a co-expert; a lay person; an authority; an accomplice or a potential critic.

When both interviewer and interviewee share background knowledge and a profound interest in the topic, the expert interview can go beyond data and provide analytical power, to 
be theory-generating and qualify as research in its own right. By problematising the concept of 'the expert' we can make politically-significant research decisions that expand the reach of the 'expert interview' using a more democratic understanding of 'expert'. This form of expert interview can be called a 'critical conversation': a methodology dependent on the relationality inherent in the situation, in the relationship between the interviewee and interviewer, and the relationship of each person to the question and material under discussion.

Such a critical conversation has a tight focus and intentionality enabled by the shared background and interest in the issues under discussion. A critical conversation article is a way to showcase the wisdom of experts, who may not be academics or writers, and share their wisdom more widely in written form. These are all reasons that support presenting the critical conversation edited but intact. Arguably, an interview article that showcases such a critical conversation transcends commentary or op-ed status and counts as a 'full research' article.

\section{Notes towards a postdigital dialogue (Petar and Gordon)}

When Plato was writing his Socratic dialogues, he was alone with his papyrus and stylus. Phaedrus, Critias, Timaeus, and of course Socrates, are historical persons - and it is likely that Plato's written dialogues were based on some sort of oral exchange with these people. Yet, we learn about their thoughts and utterances only through the lens of Plato's writing, and this inevitably ends with Socrates always 'winning' the debate. Written in the postdigital world, dialogues in Learning in the age of digital reason (Jandrić 2017) and contributions to this article have a very different character. All interlocutors have authorised their contributions before publication; each and every word has a clearly identifiable author.

However, that does not make these texts fully 'authentic'. Each conversation in Learning in the age of digital reason has undergone two (usually blind) reviews, proofreading, copy-editing; later conversations have been shaped (through changes in their authors' thinking) by comments of people who read earlier conversations. While it is safe to assume that comments and reviews have arrived from living human beings, selection of these human beings was somewhat automated. Many readers have arrived at these texts through the mediation of algorithms - through tools such as academic referencing services, social networks, and automated mailing lists. Similarly, contributions to this article have been edited, ordered, discussed, reviewed, and then again proofread and copy-edited; the dynamics of collaboration in a shared online document have enabled authors to draw on each other's thoughts, in a manner that would not be possible without digital technologies.

Plato is the only author of his dialogues, however, this postdigital dialogue is (1) directly authored by 18 people, (2) indirectly authored by at least 80 contributors to and reviewers of Learning in the age of digital reason (Jandrić 2017), (3) even more indirectly authored by tens of thousands of readers, many of whom have been chosen by algorithms, and (4) shaped by specific collaboration through working on a shared online document. While our present academic conventions still function in essentially Platonic ways - where one, easily identifiable author, produces knowledge and disseminates it to others - this article provides a prime example of ways in which our postdigital environment can shape different forms of interactions between authors and readers. Accepting Georgina's view that dialogues have potential to be full research articles - the view that Petar firmly held when he initiated this dialogic experiment - we now need to ask some important questions. Who is/are the author(s) of this article? How does this 
human/cultural cognitive system of knowledge production and dissemination reflect not only the nature of knowledge, but also that of education and politics?

\section{Conclusion (All authors)}

Disclaimer: While we share an affinity of politics this conclusion is not consensual or homogenous.

Considerations provided by the lens of a historical perspective, would suggest that we have merely scratched the surface of the strangeness and nuance of the digital world - and the digital has pushed us into the even stranger world of the postdigital. The postdigital drags the digital into the mud and rubs its nose in the complexities of everyday practice. It provides a challenge to the banality of non-thinking our way through the rise of learning machines and an understanding of 'old' and 'new' media as cohabiting artefacts. Further, through doing so, it explores questions around where we choose to place 'value' in our discourse about technology. A postdigital critical pedagogy hopes to reclaim the digital sphere as a commons, for the production of surplus consciousness and educational superabundance. Postdigital dialogue is crucial for both illuminating the hegemonic myth of technological development and unmasking the promise of capitalist prosperity, and for developing emancipated and creative democratic subjectivities and relations.

The shift towards the postdigital provides possibilities for unlearning in order to relearn, together; this is hope. However, theorizing alone will not bring such hope into being, and postdigital dialogue needs to conscientize and concretize its own politics. Postdigital (critical) pedagogies require a healthy dose of paranoia to allow the incommensurable and unforeseeable to breathe. Postdigital dialogue generates genuine, substantive, radical or participatory democracy, focusing on the interactive over the institutional, thus committing and contributing to political struggles in, against and beyond capitalism (Holloway, 2016). For doing so, a task for postdigital organic intellectuals is to challenge populism and education and move education beyond training for the capitalist machine.

Postdigital dialogue provides a space of and for learning, struggle, and hope - and this experimental article attempts to walk our talk by engaging in prefigurative postdigital dialogue about postdigital dialogue, its possibilities and opportunities. Based on previous experiments experiences of writing collectively (e.g. Editors' Collective 2018), we are tentatively confident that this article produces more knowledge than the arithmetic sum of its constituent parts. Interstitial spaces between authors' research interests offer important insights into the breadth and depth of the postdigital challenge; overlaps and reoccurring themes are good indicators of pressing issues raised by and through postdigital dialogue.

We are at the brink of a postdigital age, still in its infancy. Yet we already know that we cannot turn back. Jeremy explains, earlier in this article, that being at the 'worse end' of the 'digital divide' does not imply living an 'analogue' life - but merely a non-privileged digital life. Following a similar line of argument suggests that doing traditional research and collaboration in the postdigital age cannot be equated to betting on the winning horse. As traditional forms of research increasingly fail to describe our current reality, the previous winning horse (traditional research) needs to adapt to a new racing track (postdigital reality) and to new racing rules (of postdigital dialogue). We hope that this experimental postdigital 
dialogue on postdigital dialogue might serve as a practical and theoretical starting point for retooling our educational and research toolbox to adapt to and shape our postdigital reality.

\section{Open Review 1 (Ben)}

\section{Postdigital signals}

Reading this provocative dialogue on the contemporary postdigital condition reminded me of the morning I discovered a pair of legs and a tangled knot of wires dangling through my office ceiling. Finally, WiFi was being installed, accompanied by institutional promises of seamless connectivity and flexible working. It struck me however that the immateriality of this new wireless connectivity presented itself in the materialities of the labouring body of the installer, his toolbelt, and the plasticity of the network cables hanging above me. The floating ephemerality of a wireless digital experience in the cloud is matched by the enduring materiality of bodies, objects and spaces.

Adrian Mackenzie, in Wirelessness (2010: 3) captures the 'insignificance and blandness' of wireless networks, but also how they activate and catalyse 'experiential modifications'. The state of 'wirelessness designates an experience trending toward entanglement with things, objects, gadgets, infrastructures, and services' which, he argues, affects people's movements, relations, feelings, and change (5). Wirelessness is a postdigital condition, a merging of materially embodied experiences with the pulsations of invisible infrastructures through connected objects and things. But like all seemingly 'immaterial' digitality, it also depends on the human hands of digital workers, the inscription of the digital textuality of code, the hard plastics and metals of hardware, and the distant processing of cloud storage centres.

Across the contributions to this dialogue on postdigitality, many converge on the central point that computer code, algorithms, data infrastructures, and wireless signals are intricately bound to everyday lives, bodies, relationships, politics, culture, economics, health, science, education, and more. They raise pressing issues about disappearing distinctions between digitality and 'humanness', collectively concerned, as Jeremy Knox notes, to 'get more out of this relationship' than the formalization of 'human performance' by Silicon Valley's software developers - the programmers of our postdigital condition. Several seek critical postdigital scholarship and pedagogy to reclaim the digital sphere as a public good rather than a source for extracting value by platform capitalism.

The state of wirelessness raises a further challenge for postdigital scholarship in education. It concerns signals and detection. As schools and universities are increasingly inhabited by machine learners - in the shape of learning analytics and adaptive platforms that track, profile and learn from students' activities in order to 'personalize' their education - the student is treated as a source of signals or proxies for learning. Many of these signals are impossible to detect by a human educator. Embodied activity becomes invisible signals transmitted to the analytics platform, where those signals can be decoded, categorized, calculated, and then connected and compared with huge datasets of other signals. The student as signal-producing system in the learning environment ideally becomes a student model inside the algorithmic machine, within which personalized feedback is generated to instruct and 
recode students' capabilities and behaviours, all beyond the human capacity of the educator to detect.

The desire to detect and decode student signals is expanding as ideas about 'precision education' and personalized learning take root in educational research and software development. New 'precise' forms of educational data include signals that reflect cognition, and socio-emotional signals detected by facial recognition or scraped from the skin by wearable biometrics. New neurotechnology headsets can capture brainwave signals indicating task attention and engagement, while data-centric genomics research seeks signals from DNA to predict educational attainment, achievement and intelligence. These signals are typically postdigital traces-simultaneously made up of biologically embodied processes, socioculturally embedded activities, and sociotechnically encoded computation. However, even basic semiotics teaches that signals and what they signify are not always coterminous. Treating keystroke patterns, biometrics, brainwave oscillations, and DNA as invisible yet precise signals of learning for detection by software risks producing encoded student models with fuzzy relations to their embodied twins. Research in these postdigital 'precision' sciences of signal detection and decoding, as the dialogue collected here demonstrates, is an urgent priority for future educational scholarship.

\section{Open Review 2 (Andrew)}

As a co-editor of an e-learningly-centric journal these two ideas put together, postdigital and dialogue, often appear on the horizon of submissions, heading out of sight. What is within plain sight is a whole lot of very uncritical research. The problem for any new-media-ish journal looking to contribute critical theoretical scholarship to the field is that it is overloaded with technical stories of digital efficiencies in education (mainly meaning education systems) that engage in and/or invite very little theorisation. This paper provides an important provocation and energisation for this theoretical problem.

Jandrić gets right to the heart of the matter here with one of what I would like to call the dialogical diabolicals (the ideas that get thrown around in more or less un-dialogical ways and that highlight a significant problem with digital discourses in education) when he states digital "technologies have provided new affordances for dialogue" - from my perspective that word affordance is a dialogic killer. It's the kind of killer that Ryberg recognises as a rhetorical device, and one that tends to ask (or demand) less of the imagination because, mainly, its served up to mean the presumed 'benefits' of a digital thing rather than to invite a critique of the complexities of relationships that the authors of this dialogue are dialoguing on/in/with.

Here's another killer to look out for: ubiquity. If I read another submission that has ubiquitous, ubiquity, or ubiquitousness in the introduction or abstract I will eat my data (Bowers 2000). The tendency to open up an argument with some kind of reference to ubiquity is problematic - which is not to say that there's not a point to using this word, but rather that when it appears in an argument it tends to serve simply to justify the research rather than to be a point of discussion. What does it mean to talk about ubiquity and in particular, following Knox, what does the imagined saturational ubiquity mean in an indirect sense? For instance, what does it mean for the classification of a community as needing philanthropic intervention so as to ensure each child is connected to a digital device in order to have a chance, rather than what does it take to promote and organise the social and political world in such as way so as to make access 
to devices inconsequential or at least less consequential for school outcomes (and to keep in mind the problem of stressing any kind of relation between school outcomes and access to digital devices).

In Aotearoa New Zealand a new digital technology curriculum went 'live' this year, 2018. Unsurprisingly, the New Zealand Ministry of Education's initiative to code digital technology into the national compulsory school curriculum (a curriculum that extends to early childhood education - see below) has been seen as way to address disadvantage. For instance, in the discussion around the development of the new digital curriculum the nation heard from the Principals' Federation President that teachers should focus on how they integrate the new curriculum in disadvantaged communities, explaining: "They'll be the ones working in 10 or 20 years. Unless they are given opportunities in this area, and resources to excel in this area, they won't be contributing to the economy in the way the Government envisions" (Stuff 2017). The President of the Principal's Federation has possibly been misquoted, and certainly I am taking his words out of context, but it seems to me the provocation here is worth considering: disadvantaged children are the ones who will be working in 10 to 20 years... working, it follows, for the digital economy in one way or another. Whether that work is to their advantage or not is another matter.

The NZC digital technology curriculum is another example of what McGregor, in this contribution, explains as a "fetishization of lifelong learning, as a panacea for retaining competitive advantage". The economics advantages are not being realised quickly enough for industry here in New Zealand. In July 2016 the media reported "The change [the proposed new digital curriculum] got a lukewarm reception from the IT industry, which said the move was 'like telling a subject as essential as maths that they have to be a part of PE'" (Stuff 2016). The industry also said it was "looking for leadership, not two years of meetings and reviews" (Stuff 2016). In other words, it is not looking for the 'prefigurative' dialogue that, following Asher's argument in this paper, is essential to the "democratic values and objectives" in education.

Moving from this compulsory school curriculum problem to the higher education scenario, the anxieties appear more to be around the executive question: do we have enough online learning to get a good university ranking? In this scenario lecturing staff are obligated to turn some of the teaching hours into online hours. If a "postdigital critical pedagogy wants to further the Internet that is useful to the people that they can shape for their own uses" (Suoranta), this shift to learning online might be an excellent opening up for the student. It could be quite radical. It could introduce or at least revive "problems and possibilities for horizontal and vertical pedagogical praxis" (Ford). However... it is at the same time an emotional burden that requires unpacking (Steketee) - can we imagine a new academic literacies core curriculum paper for undergraduates entitled something like Digital Anxieties: How to switch on and off your learning?

Now, as well as bleeding heart editor longing to break down the digital walls of the monoliths of digital monologue in the study of digital technocracies in education, my writing in the digital domain is primarily focused on how the 'digital age' impacts on early childhood centre communities. So I'd like to conclude this open review by engaging with the ways in which Postdigital Dialogue can inform those communities for whom the digital debate is a very thin fence that no-one can sit on, and for whom the word postdigital could be a release from the polemic arguments between the technology minded and the nature minded which present to 
them (a release developed in the work of Affrica Taylor and the Common Worlds Collective) (see Taylor 2013 and Common Worlds Research Collective 2018).

Working conditions: There is argument in this paper that postdigital dialogues engage with exploitation - and that includes exploitation of early childhood centre communities. The digital wall around the early childhood centre community is one that is broken out of rock, as Ryberg illustrates. That exploitation extends to the ways in which the teachers and learners in an early childhood centre are engaged in their "unpaid digital labour" (Peters \& Bulut, 2011), buying into the idea that they are preparing for a life of learning and a life of contributing to a big data economy, and influencing both educational aims and methods (including the very ways in which the teacher and child come to think about thinking). A postdigital dialogue then engages with, in Hayes' and Suoranta's words: the "economically-based assumptions and individualised agendas, that restrict how we might collectively imagine alternative futures" in order to open up the "horizon of solidarity in learning and co-operation".

Pedagogies: The authors of this paper also contribute a strong argument for the pedagogical possibilities of a Postdigital Dialogue for early childhood centre communities. For instance, Lacković invites the teachers and learners to explore the "profusion and connectedness between the body and the mind, the image and the concept, the artefact and the dialogue, the art and the science, the technological and the human" - challenging the distinctions of real and technological that construct some curriculum materials and approaches as natural and others as, well, not natural. In addition, Smith and Knox invite questions concerning our inadvertent promotion of new media and the ways in which that media leads thinking - in early childhood education the rise of digital assessment tools would be one such pedagogy to question critically. Finally, returning to the idea of the ubiquitous affordances for lifelong learning, the pedagogical impetus in this paper is for early childhood centre communities to get stuck into "dragging digitalisation and the digital - kicking and screaming - down from its discursive celestial, ethereal home and into the mud" (Ryberg). That's about the early childhood centre community engaging in an ongoing, open, postdigital dialogue as a critical element of the curriculum.

\section{References}

Adorno, T. W., \& Horkhemier, M. (2002). Dialectic of enlightenment: philosophical fragments. Stanford, CA: Stanford University Press.

Peters, M. A., \& Bulut, E. (Eds). (2011). Cognitive capitalism, education and digital labor. New York: Peter Lang.

Albert, M. (2006). Realizing Hope: Life Beyond Capitalism. New York: Zed Books.

Allen, C. (2012). A transnational Native American studies? Why not studies that are transindigenous?. Journal of Transnational American Studies, 4(1), 1-23.

Allman, P. (1999). Revolutionary Social Transformation. Westport: Bergin \& Garvey.

Amsler, S. (2015). The Education of Radical Democracy. London: Routledge

Ascott, R. (2008). Technoetic Arts. Bristol: Intellect.

Asher, G. (2015). Criticality in Postgraduate Research and Writing. In E. Ryan \& T. Walsh, (Eds.), Writing your thesis: A guide for postgraduate students. MAynooth, Ireland: MACE Press.

Asher, G. (2017). The Porous University: Opening up the University; Being and becoming critically academically literate? Presentation for The Porous University Symposium: The 
Porous University - A critical exploration of openness, space and place in Higher Education, May, 2017., University of the Highlands and Islands. https://www.raggeduniversity.co.uk/2017/06/05/the-porous-university-opening-up-theuniversity-being-and-becoming-critically-academically-literate-by-gordon-asher/. Accessed 15 June 2018.

Ball, S. J. (2012). Global Education Inc. New Policy Networks and the Neo-Liberal Imaginary. London: Routledge

Bassett, C. (2015). Plenty as a response to austerity? Big Data expertise, cultures and communities. European Journal of Cultural Studies, 18(4-5), 548-563, https://doi.org/10.1177/1367549415577394.

Bianchi, C. (2018). Reflections on the implications of western theories on indigenous populations: Decolonizing and indigenizing the classroom. In G. Dei \& C. Jaimungal (Eds.), Indigeneity and decolonial resistance: Alternatives to colonial thinking and practice (pp. 5175). Gorham, ME: Myers Education Press.

Bogner, A., \& Menz, W. (2009). The theory-generating expert interview: Epistemological interest, forms of knowledge, interaction. In A. Bogner, B. Littig, \& W. Menz (Eds.), Interviewing experts (pp. 43-80). Basingstoke, UK: Palgrave Macmillan.

Bogner, A., Littig, B., \& Menz, W. (2009). Interviewing experts. Basingstoke, UK: Palgrave Macmillan.

Bookchin, M. (1990). The Meaning of Confederalism. The Anarchist Library. http://theanarchistlibrary.org/library/murray-bookchin-the-meaning-of-confederalism.

Accessed 15 June 2018.

Bowers, C. (2000). Let them eat data: How computers affect education, cultural diversity and the prospects of ecological sustainability. Athens, GA: The University of Georgia Press.

Boyd, D., \& Crawford, K., (2012). Critical Questions for Big Data. Information, Communication \& Society, 15(5), 662-679.

Brookfield, S. (2005). The Power of Critical Theory for Adult Learning and Teaching. Buckingham, UK: Open University Press.

Burbules, N. C. (1993). Dialogue in teaching: Theory and practice. New York: Teachers College Press.

Canaan, J. (2011). Critical pedagogy, in, against and beyond the neoliberalised university. ESRC seminar Global Citizenship as a Graduate Attribute, UCL, 14 October http://andreasbieler.net/wp-content/files/Canaan\%20Critical\%20pedagogy.pdf. Accessed 15 June 2018.

Chomsky, N. (2018). The growth of right-wing forces is ominous. ZNet, 24 August. https://zcomm.org/znetarticle/the-growth-of-right-wing-forces-is-ominous/. Accessed 15 June 2018.

Common Worlds Research Collective (2018). Main. http://commonworlds.net/. Accessed 7 September 2018.

Cowden, S., \& Singh, G. (2013). Acts of Knowing: Critical Pedagogy In, Against and Beyond the University. London: Bloomsbury.

Cramer, F. (2014). What is Post-digital? A Peer-Reviewed Journal About, 3(1). 
Darder, A. (2018). Critical Leadership for Social Justice Unveiling the Dirty Little Secret of Power and Privilege. In McLaren, P. \& Soohoo, S. (Eds.), Radical Imagine-Nation: Public Pedagogy \& Praxis (pp.41-73). New York: Peter Lang.

Darder, A. (2015). Freire and Education. New York: Routledge.

Darder, A. (2017). Reinventing Paulo Freire: A Pedagogy of Love. New York: Routledge

Davie, G. (1990). The Democratic Intellect. Edinburgh, Edinburgh University Press.

Dean, J. (2016). Crowds and Party. New York: Verso.

Debord, G. (2006). La Société du Spectacle. Paris: Gallimard.

Domoff, S. E., Harrison, K., Gearhardt, A. N., Gentile, D. A., Lumeng, J. C., \& Miller, A. L. (2017). Development and validation of the Problematic Media Use Measure: A parent report measure of screen media "addiction" in children. Psychology of Popular Media Culture. http://dx.doi.org/10.1037/ppm0000163.

Editors' Collective (2018). Mission Statement. http://editorscollective.org.nz/. Accessed 15 June 2018.

Emejulu, A., \& McGregor, C. (2016). Towards a Radical Digital Citizenship in Digital Education. Critical Studies in Education. DOI: 10.1080/17508487.2016.1234494.

Eubanks, V. (2018). Automating Inequality: How High-Tech Tools Profile, Police, and Punish the Poor. New York: Macmillan.

Flick, U. (2014). An introduction to qualitative research (5th ed.). Thousand Oaks CA: Sage.

Ford, D. R. (2018). Politics and pedagogy in the 'post-truth' era: Insurgent philosophy and praxis. New York: Bloomsbury.

Freire, P. (1970). Pedagogy of the Oppressed. New York: Continuum.

Giroux, H. (2017). Rethinking Higher Education in a Time of Tyranny. Truthdig, 14 October. https://www.truthdig.com/articles/rethinking-higher-education-time-tyranny/. Accessed 15 June 2018.

Giroux, H. (2018). American Nightmare: Facing the Challenge of Fascism. San Francisco: City Lights.

Goodfellow, I., Bengio, Y., \& Courville, A. (2016). Deep Learning. Cambridge, MA: MIT Press.

Gorz, A. (1997). Farewell to the Working Class. London: Pluto Press.

Gunn, R. (2014). New Priorities. Bella Caledonia, 4 October. https://bellacaledonia.org.uk/2014/10/04/new-priorities/. Accessed 15 June 2018.

Haas, A. M. (2008). Wampum as hypertext: An American Indian intellectual tradition of multimedia theory and practice. Studies in American Indian Literatures, 19(4), 77-100. doi:10.1353/ail.2008.0005.

Haiven, M. (2014). Capitalism's crisis of value and imagination. Truthout, 8 February. https://truthout.org/articles/capitalisms-crisis-of-value-and-imagination/. Accessed 15 June 2018.

Hall, R., \& Winn, J. (Eds.) (2017). Mass Intellectuality and Democratic Leadership in Higher Education. London: Bloomsbury.

Hall, S. (1996). The meaning of New Times. In D. Morley \& K-H Chen (Eds.), Stuart Hall: Critical Dialogues in Cultural Studies (pp. 222-236). London: Routledge. 
Hallewell, M. J., \& Lacković, N. (2017). Do pictures 'tell'a thousand words in lectures? How lecturers vocalise photographs in their presentations. Higher Education Research \& Development, 36(6), 1166-1180.

Harvey, D. (2003). The Fetish of Technology: Causes and Consequences. Macalester International, 13(7).

Hayes, S. (2015). Counting on the use of technology to enhance learning. In P. Jandrić \& D. Boras (Eds.), Critical Learning in Digital Networks (Research in Networked Learning) (pp. 1536). New York: Springer.

Hayes, S. (2018). Invisible labour: do we need to reoccupy student engagement policy? Learning and Teaching, 11(1): 19-34.

Hayes, S. (forthcoming, 2018). The Labour of Words in Higher Education: is it time to reoccupy policy? Leiden: Brill.

Hayes, S., \& Bartholomew, P. (2015). Where's the Humanity? Challenging the Policy Discourse of Technology Enhanced Learning. In J. Branch, P. Bartholomew \& C. Nygaard (Eds.), Technology Enhanced Learning in Higher Education. London: Libri.

Hayes, S., \& Jandrić, P. (2014). Who is Really in Charge of Contemporary Education? People and technologies in, against and beyond the neoliberal university. Open Review of Educational Research 1(1), 193 - 210.

Hearne, J., \& LaPensée, E. (2017). "We All Stand Side by Side": An interview with Elizabeth LaPensée. Studies in American Indian Literatures, 29(1), 27-37. doi:10.5250/studamerindilite.29.1.0027.

Hearne, J. (2017). Native to the device: Thoughts on digital indigenous studies. Studies in American Indian Literatures, 29(1), 3-26. doi:10.5250/studamerindilite.29.1.0003.

Helms, G., French, L., Bradley, L. \& the Variant Editorial Group (2016). Divergence and agonism: the different, the other and the one who disagrees. Variant Report.

Holloway, J. (2016). In, Against and Beyond Capitalism: The San Francisco Lectures. Oakland, CA: PM Press.

Jandrić, P., Knox, J., Besley, T., Ryberg, T., Suoranta, J., \& Hayes, S. (2018). Postdigital Science and Education. Educational Philosophy and Theory, 50(10), 893-899. https://doi.org/10.1080/00131857.2018.1454000.

Jandrić, P. (2017). Learning in the Age of Digital Reason. Rotterdam: Sense.

Kahn, R. (2010). Critical Pedagogy, Ecoliteracy, and Planetary Crisis. New York: Peter Lang. Kane, L. (2001). Popular Education and Social Change in Latin America. Latin American Bureau.

Kellner, D. (2001). Globalisation, Technopolitics and Revolution. Theoria, 48(98), 14-34.

Knight, S., \& Littleton, K. (2015). Dialogue as data in learning analytics for productive educational dialogue. Journal of Learning Analytics, 2(3), 111-143. http://dx.doi.org/10.18608/jla.2015.23.7.

Lacković, N. (2010). Creating and reading images: towards a communication framework for Higher Education learning. Seminar. net, 6(1).

Lacković, N. (2018). Analysing videos in educational research: an "Inquiry Graphics" approach for multimodal, Peircean semiotic coding of video data. Video Journal of Education and Pedagogy, 3(6). DOI: https://doi.org/10.1186/s40990-018-0018-y.

Lakoff, G., \& Johnson, M. (2008). Metaphors we live by. Chicago: University of Chicago Press. 
Lawson, C., Beer, C., Rossi, D., Moore, T. \& Fleming, J. (2016). Identification of 'at risk' students using learning analytics: the ethical dilemmas of intervention strategies in a higher education institution. Educational Technology Research and Development, 64(5), 957-968.

Lyotard, J. F. (1984). The postmodern condition: A report on knowledge, trans. B. Massumi. Minneapolis: University of Minnesota Press.

Mackenzie, A. (2010). Wirelessness: Radical Empiricism in Network Cultures. London: MIT Press.

Mackenzie, D., \& Wajcman, J. (1999). The social shaping of technology. Buckingham, UK: Open University Press.

Marx, K. (1867/2003). Capitalism and the Modern Labour Process. Capital, Vol 1.. In R. C. Scharff \& V. Dusek (Eds.), Philosophy of Technology: The Technological Condition: An Anthology. Oxford, UK: Blackwell \& Minneapolis: University of Minnesota Press.

Mojtabai, R., Olfson, M., \& Han, B. (2016). National trends in the prevalence and treatment of depression in adolescents and young adults. Pediatrics, 138(6), 1-12. doi:10.1542/peds.20161878.

Morozov, E. (2013). To Save Everything, Click Here: Technology, Solutionism, and the Urge to Fix Problems that Don't Exist. London: Allen Lane.

Mouffe, C. (2013). Agonistics: Thinking the World Politically. New York: Verso.

Noble, S. U. (2018). Algorithms of Oppression: How Search Engines Reinforce Racism. New York: New York University Press.

O’Neil, C. (2017). Weapons of Math Destruction: How Big Data Increases Inequality and Threatens Democracy. London: Penguin.

Peters, M. A.; Jandrić, P. \& Hayes, S. (2018). The curious promise of educationalising technological unemployment: What can places of learning really do about the future of work? Educational Philosophy and Theory, OnlineFirst. https://doi.org/10.1080/00131857.2018.1439376.

Peters, M. A. (2015). Interview with Pierre A. Lévy, French philosopher of collective intelligence. Open Review of Educational Research, 2(1), 259-266. https://doi.org/10.1080/23265507.2015.1084477.

Peters, M. A. \& Jandrić, P. (2018). The Digital University: A Dialogue and Manifesto. New York: Peter Lang. https://doi.org/10.3726/b11314.

Raheja, M. (2017). Imagining indigenous digital futures: An afterword. Studies in American Indian Literatures, 29(1), 172-175. doi:10.5250/studamerindilite.29.1.0172.

Rancière, J. (2010). Dissensus: On Politics and Aesthetics. New York: Continuum.

O'Connor, K. (2015). Don't they represent us?: A discussion between Jacques Rancière and Ernesto Laclau. https://www.versobooks.com/blogs/2008-don-t-they-represent-us-adiscussion-between-jacques-ranciere-and-ernesto-laclau. Accessed 15 June 2018.

Rikowski, G. (2003). Alien life: Marx and the future of the human. Historical Materialism, 11(2), $121-164$.

Roberts, P. (1996). Rethinking Conscientisation. Journal of Philosophy of Education, 30(2), 179-196. https://doi.org/10.1111/j.1467-9752.1996.tb00390.x.

Romero, C. (2017). Toward an indigenous feminine animation aesthetic. Studies in American Indian Literatures, 29(1), 56-87. doi:10.5250/studamerindilite.29.1.0056. 
Sclater, N., Peasgood, A., \& Mullan, J. 2016. Learning Analytics in Higher Education: A review of UK and international practice. JISC. https://www.jisc.ac.uk/sites/default/files/learninganalytics-in-he-v3.pdf. Accessed 15 June 2018.

Shalom, S. (2008). A Political System for a Good Society. ZNet, 31. December. https://zcomm.org/znetarticle/a-political-system-for-a-good-society-by-stephen1-shalom.

Accessed 15 June 2018.

Smith, M. (2011). AMI \& Ed.: moving image art vs dead modernist artists'. In M. Ciastellardi, M., C. M. de Almeida, \& C. A. Scolari (Eds). McLuhan Galaxy Conference: understanding media today. Barcelona: Universitat Oberta de Catalunya.

Smith, M. (2012a). Artists' moving image in the digital classroom: implementing contemporary time-based art practices within secondary schools in England. Paper presented at National Visual Arts Educators Conference. Canberra: National Art Gallery.

Smith, M. (2012b). Me... and others. Video portraits, co-created with teenage students attending referral unit. Leicester: Pedestrian Gallery.

Smith, M. (2017). Artists' Moving Image. Online education resource. www.artistsmovingimage.org. Accessed 15 June 2018.

Stafford, B. M. (1993). Body criticism: Imaging the unseen in enlightenment art and medicine. Cambridge, MA: MIT Press.

Stafford, B. M. (1998). Good looking: Essays on the virtue of images. Cambridge, MA: MIT Press.

Stafford, B. M. (1996). Artful science: Enlightenment entertainment and the eclipse of visual education. Cambridge, MA: MIT Press. Stafford, B. M. (2001). Visual analogy: Consciousness as the art of connecting. Cambridge, MA: MIT Press.

Stafford, B. M. (2007). Echo objects: The cognitive work of images. Chicago: University of Chicago Press.

Stuff (2016). Digital technology coming to the New Zealand Curriculum. Stuff, July 7. http://www.stuff.co.nz/national/education/81763452/Digital-technology-coming-to-the-NZCurriculum. Accessed 7 September 2018.

Stuff (2017). Nikki Kaye reveals shakeup for school curriculum. Stuff, June 28. https://www.stuff.co.nz/national/education/94163443/shake-up-for-school-curriculumrevealed. Accessed 7 September 2018.

Striphas, T. (2015). Algorithmic Culture. European Journal of Cultural Studies, 18(4-5), 395412. DOI: $10.1177 / 1367549415577392$.

Susi, T. (2006). Tools and Artefacts-Knowing'Where-from'Affects Their Present Use. Proceedings of the 28th annual conference of the cognitive science society in cooperation with the 5th international conference of the cognitive science society (pp.2210-2215). Vancouver, CA: Cognitive Science Society.

Taylor, A. (2013). Reconfiguring the natures of childhood. Abingdon, England: Routledge. Taylor, P. V. (1994). Dialogue, conversation and praxis. In YMCA George Williams College' ICE301 Lifelong learning, Unit 1 Approaching lifelong learning. London: YMCA George Williams College. http://infed.org/mobi/dialogue-conversation-and-praxis/. Accessed 15 June 2018. 
Twenge, J. (2017). iGen: Why today's super-connected kids are growing up less rebellious, more tolerant, less happy--and completely unprepared for adulthood--and what that means for the rest of us. New York, NY: Atria Books.

University of Cambridge (2018). Cambridge Educational Dialogue Research Group. https://www.educ.cam.ac.uk/research/groups/cedir//. Accessed 15 June 2018.

van Barneveld, A., Arnold, K.E., \& Campbell, J.P. (2012). Analytics in Higher Education: Establishing a Common Language. Educause Learning Analytics (ELI) Paper. https://library.educause.edu/ /media/files/library/2012/1/eli3026-pdf.pdf. Accessed 15 June 2018.

Vásquez, G. R. (2010). Education from inside deep America. In L. Meyer \& B. M. Alvarado (Eds.), New World of Indigenous Resistance (pp.277-283). San Francisco: City Lights Books. Vygotsky, L. (1978). Interaction between learning and development. Readings on the development of children, 23(3), 34-41.

Wachter-boettch, S. (2017). Technically Wrong: Sexist Apps, Biased Algorithms, and Other Threats of Toxic Tech. New York: Norton and Co.

Wallin, J. J., \& Sandlin, J. A. (2018). Out of our minds: A haphazard consideration of paranoia and its antecedents. In J. A. Sandlin \& J. J. Wallin (Eds.), Paranoid pedagogies: Education, culture, and paranoia (pp. 1-26). New York: Palgrave Macmillan.

Weeks, K. (2007). Life Within and Against Work: Affective Labor, Feminist Critique, and PostFordist Politics. Ephemera, 7(1), 233-249.

Williamson, B. (2015). Smarter learning software: Education and the big data imaginary. Presented at the Big Data—Social Data, Warwick. http://dspace.stir.ac.uk/handle/1893/22743. Accessed 15 June 2018.

Williamson, B. (2018). Silicon startup schools: technocracy, algorithmic imaginaries and venture philanthropy in corporate education reform. Critical Studies in Education, 59(2), 218236, DOI: $10.1080 / 17508487.2016 .1186710$. 